\title{
RETRADUZIR É PRECISO ${ }^{1}$
}

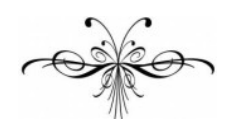

MAURI FURLAN

Resumo: Da tradução dos clássicos na Antiguidade à tradução dos clássicos hoje, o Ocidente conheceu distintas concepções e modos de traduzir. Chegados ao atual momento histórico e maturidade linguística, com a possibilidade/necessidade de retraduzir os clássicos e reabrir o acesso a eles, deparamo-nos com o desafio de adentrarmos outras concepções e modos de traduzir, de ousarmos produzir "traduções-textos” (Meschonnic).

Palavras-chave: Meschonnic; Berman; retraduzir; tradução-texto; clássicos.

\begin{abstract}
From the translation of the classics in the Antiquity to the translation of the classics today, the West has got acquainted to different conceptions and ways of translating. At our current historical moment and linguistic maturity, in which the possibility/need to retranslate the classics and reopen access to them presents itself, we are faced with the challenge of dealing with other conceptions and ways of translating, of daring to produce "translation-texts" (Meschonnic).
\end{abstract}

Keywords: Meschonnic; Berman; retranslation; translation-text; classics.

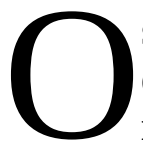

s clássicos, como grandes textos da literatura universal, só podem ser lidos universalmente mediante tradução. E como afirma o téorico francês Henri Meschonnic (1999:54): Um grande texto literário comporta uma tradução em si também grande, isto é, “que ela tenha tudo de uma obra, que ela dure como uma obra, com um mesmo modo de atividade". 2 A tradução é um prolongamento inevitável da literatura, e deve prestar contas a ela.

\footnotetext{
${ }^{1}$ Conferência proferida no I Congresso Luso-Brasileiro Traduzir e Publicar os Clássicos, Universidade de Coimbra, em 22/11/2012.

2 “'Un grande texte n'entraîne pas qu'une traduction en soit grande aussi, c'est-à-dire qu'elle ait tout d'une oeuvre, qu'elle dure comme elle, avec un même mode d'activité.” Todas as traduções apresentadas são de minha autoria.
} 
As grandes obras literárias são a melhor expressão da estética mais elevada do período em que foram produzidas. Estética esta que se diferencia sensivelmente entre os períodos históricos do Ocidente, algo que se explica como reflexo de mudanças na cosmovisão, na concepção de linguagem e de literatura. E a tradução, porque é uma prática de escritura de textos, reflete, de certa forma, a mesma estética literária do período em que é produzida. Ou seja, as concepções históricas de escritura relacionam-se com as de tradução, que, por sua vez, interagem com os modos de tradução praticados (Furlan 2002). Se pensarmos, por exemplo, na prática de tradução nos períodos históricos da Antiguidade ao Renascimento, em que tantos clássicos foram produzidos, e como hoje são traduzidos, perceberemos que o modo de tradução foi algo distinto em cada momento histórico. Grosso modo, vemos que [1] os Romanos traduziram romanizando a expressão e o conteúdo, adaptando, suplantando o original. A tradução para eles era mais um exercício de estilística comparada, uma vez que a sociedade letrada era no mínimo bilíngue e não tinha necessidade imperiosa das traduções do grego. [2] A tradução literária do Medievo - de modo distinto ao da religiosa constituiu-se como verdadeiros comentários, com o desejo maior de entender a Antiguidade e o sentido do texto. A tradução era o meio de transmissão da mensagem, e importava sobremodo aquilo que se considerava a fidelidade ao pensamento e aos objetivos da mensagem. Isso justifica tanto a tradução totalmente livre da literatura, produzida sobretudo a partir do século XIII, quanto a tradução fortemente literal de textos religiosos: a palavra é então a unidade sagrada a ser traduzida, plena de sentido. [3] O Renascimento traduziu tentando readquirir a estética clássica - cujos padrões se haviam transformado ou perdido no Medievo: o neoclassicismo renascentista significou uma revolução no gosto literário do Medievo tardio, caracterizando-se pela substituição do estilo empolado da prosa medieval tardia, com sua sintaxe frouxa, períodos inconstantes, e ornamentos imitados, pelos padrões clássicos da boa dicção: “correção, clareza, ordem, variedade, elegância” (Griffiths et al. 1987:4) - e recriar a arte do original na língua de chegada ou criar um novo texto artístico, mas advogando maior proximidade com o texto fonte. A tradução é concebida como a recuperação do texto original, isto é, sem interpolações e comentários dos tradutores. É um momento de dessacralização da palavra, e da passagem à frase como unidade de tradução (Meschonnic 1999:16). O século XVI é um tempo de grande importância linguística, em que se destacam o fortalecimento das línguas vernáculas e o início de sua utilização como expressão nacional, e o desenvolvimento das literaturas nas novas línguas atrelado a um modo de tradução específico, que se serve dos ensinamentos da filologia levada à Itália pelos bizantinos. É no Renascimento que encontramos as bases de nossa concepção atual de tradução. [4] A Modernidade, que emerge na Europa sensivelmente a partir do século XVII, no referente à tradução, abarca todos os momentos e movimentos tradutórios subsequentes, mesmo os mais propriamente caracterizados como o das Belles Infidèles e o Romantismo. Aparentemente, a maioria das traduções literárias modernas almeja refletir o conteúdo e a forma do modelo primeiro, não descuidando do gênio da língua de chegada, e considerando a possibilidade de recriação da arte do original. A tradução é comumente considerada o meio de contato entre culturas mediante a comunicação, que consiste em passar um enunciado de uma língua a outra. Os mesmos ideais renascentistas pervivem até hoje, e, no século XXI, nos deparamos igualmente com tradutores e teorias da tradução que 
lutam em defesa da fidelidade ao original, do apagamento do tradutor, da preservação do sentido, e de outros valores que constituem o estigma do traduttore traditore. Entre os períodos antigos e hoje, vários houve e apresentaram suas características próprias nos modos e concepções de tradução, mas, apesar de todas as nuances, que podem demarcar maiores ou menores diferenças entre as distintas práticas tradutivas, é também possível afirmar que em todos os períodos históricos, em toda a história da tradução ocidental, houve uma inegável semelhança no modo de tradução: a primazia do sentido.

A tradução ocidental, especialmente a literária, que é uma invenção romana, costuma ser apresentada como tendo suas origens na tradução da Odisseia de Homero, por Lívio Andrônico, por volta de 250 a.C. Dos poucos fragmentos que nos chegaram daquela tradução, diz-se que variava entre a exatidão, um estilo simples, alguns desvios e alguns êxitos, embora distante da flexibilidade da língua grega (Bayet 1996:48). O que é também dizer que variava entre o conteúdo e a forma. Para alguns estudiosos, o problema essencial da teoria e da prática da tradução em todos os tempos poderia resumir-se à questão: devese ser fiel às palavras do texto ou ao pensamento contido nele? (Mounin 1965:31) Tradução literal ou tradução livre, ad uerbum ou ad sensum? A problemática da tradução, contudo, não se limita a uma breve resposta a tal questão, e tampouco é consenso geral entendê-la desta forma.

Por exemplo, uma tentativa de recolocar de modo distinto a problemática da tradução, e que faz escola até nossos dias, foi feita por Schleiermacher, no início do século XIX [1813], num breve tratado intitulado "Dos diferentes modos de traduzir" [Über die verschiedenen Methoden des Übersetzens ${ }^{3}$ ], onde o autor alemão afirma que há somente dois modos de traduzir: "Ou o tradutor deixa o autor o mais possível em paz e leva o leitor ao seu encontro, ou deixa o leitor o mais possível em paz e leva o autor ao seu encontro"4 (2011:22). Também o pensamento de Schleiermacher aponta para a questão da fidelidade, para a questão das línguas, seja no cuidado com a língua de partida, seja no cuidado com a língua de chegada. Mas, sem dúvida, um ponto importante nessa colocação é o da possibilidade da importação do estrangeiro, da alteridade, de um modo de leitura do Outro a partir do Outro mesmo. Sobre esse pensamento de Schleiermacher, teóricos contemporâneos dos Estudos da Tradução - como Lawrence Venuti, Antoine Berman, e Meschonnic - desenvolveram parte de suas reflexões, e originaram-se conceitos como domesticação x estrangeirização, tradução etnocêntrica $x$ tradução ética, tradução hipertextual $x$ tradução poética, tradução-língua x tradução-texto, etc.

Foi nas últimas décadas do século XX que começaram a surgir reflexões em torno da tradução, as quais propõem pensarmos as questões da tradução por um novo paradigma. Depois do estabelecimento das novas línguas vernáculas ocidentais no Renascimento, da busca por recuperar os textos antigos sem interpolações e comentários, e da passagem da palavra à frase como unidade de tradução - qual Fênix, que renasce a cada 500 anos! -, percebe-se hodiernamente a aceitação paulatina de uma nova concepção de escritura e, consequentemen-

\footnotetext{
${ }^{3}$ Três traduções brasileiras deste texto de Schleiermacher foram publicadas, de forma sinótica, em Scientia Traductionis, n.9, 2011, pp. 3-70.

[http://www.periodicos.ufsc.br/index.php/scientia/issue/view/1659]

4 “Entweder der Übersetzer läßt den Schriftsteller möglichst in Ruhe, und bewegt den Leser ihm entgegen; oder er läßt den Leser möglichst in Ruhe und bewegt den Schriftsteller ihm entgegen.”
} 
te, de tradução, na qual passamos da frase ao texto como unidade de tradução, numa época em que as já velhas línguas vernáculas ocidentais atingem elevado grau de amadurecimento, e que se busca novo acesso àqueles mesmos textos antigos que fundaram nossa cultura e literatura ocidentais.

Atenta-se sempre mais para a literatura como um sistema discursivo. Descobre-se que uma tradução de um texto literário deve e pode fazer o que faz um texto literário, por sua prosódia, seu ritmo, sua significância (= a produção de sentidos - rítmico, prosódico, semântico -, a partir do significante mesmo, mas ultrapassando o próprio signo), tradução não da língua mas do discurso, da escritura, que é a organização de uma subjetivação no discurso (Meschonnic 1999:12), tradução como uma das formas da individualização, da historicização do sujeito (1999:16):

Isso desloca radicalmente os preceitos de transparência e de fidelidade da teoria tradicional, fazendo-os parecer como álibis moralizantes originados de um desconhecimento, do qual a caducidade das traduções é sua paga merecida. A equivalência buscada não se coloca mais de língua a língua, com a tentativa de ocultar as diferenças linguísticas, culturais, históricas. Ela é colocada de texto a texto, trabalhando ao contrário para mostrar a alteridade linguística, cultural, histórica, como uma especificidade e uma historicidade ${ }^{5}$ (1999:16).

Meschonnic, um dos grandes proponentes dessa nova reflexão, definirá tradução como "reenunciação específica de um sujeito histórico"6 (1973:308), reenunciação que é cada vez a variável de uma invariante (1973:55); específica porque cada tradução é uma leitura, de um sujeito histórico que produz uma atividade que envolve uma língua como sistema, um inconsciente como sistema, uma ideologia como sistema, datado e situado. Cada leitura constitui cada vez um sistema de significância; cada leitor se lê na obra e nela se inscreve através de seu criador e, através do tradutor, se lê-inscreve na tradução. Cada leitura faz-se uma leitura-escritura. Cada leitura se torna outra textualização.

A escritura é a prática de um sujeito. Aquele que escreve, se escreve, aquele que lê, se lệ (1973:47).

Cada época retraduz porque lê e escreve de outro modo. O paradoxo provisório da tradução bem-sucedida (aquela que dura) é aquele da necessária reenunciação ${ }^{8}$ (1973: 424).

\footnotetext{
5 “Ce qui déplace radicalement les préceptes de transparence et de fidelité de la théorie traditionelle, en les faisant apparaître comme les alibis moralisants d'une méconnaissance dont la caducité des traductions n’est que le juste salaire. L’équivalence recherchée ne se pose plus de langue à langue, en essayant de faire oublier les différences linguistiques, culturelles, historiques. Elle est posée de texte à texte, en travaillant au contraire à montrer l'alterité linguistique, culturelle, historique, comme une spécificité et une historicité.”

6 “Ré-énontiation spécifique d'un sujet historique”.

7 “L’écriture est la pratique d’un sujet. Celui qui écrit s’écrit, celui qui lit se lit”.

8 "Chaque époque retraduit parce qu'elle lit et écrit autrement. Le paradoxe provisoire de la traduction réussie (celle qui dure) est celui de la nécessaire ré-énontiation”.
} 
Uma tal reflexão fundada sobre uma teoria histórico-materialista da linguagem põe fim ao reinado do sentido objetivo, imanente, imutável, ahistórico, próprio de uma concepção que perpetua conceitos como o da inferioridade da tradução frente ao original, fidelidade, transparência, apagamento do tradutor, etc.

Nessa mesma linha, Antoine Berman dirá que a tradução ocidental, em geral, caracteriza-se por três traços: é etnocêntrica, hipertextual e platônica, e dessa forma oculta sua essência mais profunda que é a de ser ética, poética e pensante (2012:34); e que essa essência oculta pode emergir e produzir traduções singulares sobretudo das grandes obras literárias, dos clássicos.

O pensamento dos teóricos a que me refiro - sobretudo Meschonnic e Berman $^{9}$ - mereceria uma longa e aprofundada exposição, mas trago aqui apenas alguns elementos que nos levam a refletir sobre um outro modo de traduzir que não o mais comumente praticado.

Mas o que nos estão criticando esses teóricos e que proposta de tradução têm a fazer? O que nos criticam é a ignorância em não vermos que insistir na tradução do sentido é destruir o texto primeiro.

A concepção de tradução, que vem desde Cícero, como a passagem de uma língua a outra está ligada à noção de estilo pessoal; estilo como escolha feita na e para a língua de chegada. Esse é ainda o ponto de vista de muitos profissionais da tradução, em termos de gramática contrastiva e de estilística comparada. Seus preceitos maiores são a busca da fidelidade e o apagamento do tradutor frente ao texto. O apagamento do tradutor objetiva dar a impressão de que a tradução não é uma tradução, dar uma ilusão de natural, apagar todas as particularidades que pertencem a um outro modo de significar, apagar as distâncias de tempo, de língua, de cultura. A isso Berman chama de tradução etnocêntrica, porque traz tudo à sua própria cultura, às suas normas e valores, e considera o Estrangeiro, o que se encontra fora dela, como negativo, ou, no máximo, bom para ser anexado, adaptado, para aumentar a riqueza dessa cultura. Essa tradução, que aperfeiçoa, embeleza, nacionaliza, naturaliza e modifica seu original é a que busca captar os sentidos, considerados invariantes, e os traslada à sua língua, abandonando sua forma, seu significante. Como diz Berman, o significante se torna insignificante (2012:44). A fidelidade ao sentido se opõe à fidelidade à letra - à letra estrangeira, porque é fiel à letra própria. A essência da tradução etnocêntrica funda-se sobre a primazia do sentido, que por sua vez afirma a primazia da língua de chegada. Considera-se que uma obra que não é sentida como tradução é uma obra bem escrita na língua de chegada - escrita numa língua normativa, mais normativa do que a da obra original, porque não deve causar estranhamentos lexicais e sintáticos. Esse é o ponto onde a tradução etnocêntrica torna-se hipertextual.

A tradução hipertextual produz, a partir de um texto já existente, um outro por meio da imitação, da paródia, do pastiche, da adaptação, do plágio, ou qualquer outra espécie de transformação formal, relacionando os dois textos. O objetivo é reproduzir o sistema estilístico da obra ou criar um equivalente. Depois de acreditar ter-se captado o sentido, tenta-se repassá-lo num estilo que imita o original. Ou nem isso.

\footnotetext{
${ }^{9} \mathrm{O}$ pensamento dos teóricos franceses que apresento aqui fundamenta-se em grande parte nas obras de Meschonnic de 1973 e 1999; e de Berman de 1985.
} 
O exemplo mais claro de tradução pelo sentido talvez seja o da tradução filológica, que, embora sem ambições literárias, desqualificou todos os outros tipos de tradução realizados por 'não-especialistas' em línguas e textos de determinadas áreas ou estrangeiros. O que se propõe agora não é abandonar os grandes méritos que a filologia proporcionou, como os do estabelecimento e crítica dos textos, mas afastar-se das traduções desastrosas que produz. O conhecimento "exato" de uma obra e de uma língua não habilita em absoluto à tradução e ao comentário. A filologia, ao embalsamar os textos, rompe com a tradição e torna os clássicos ilegíveis, entendiantes e estranhos à nossa sensibilidade (2012:159ss.). E com que finalidade isso é feito? Informar sobre as obras literárias e suas culturas?

Representar a tradução na maioria das vezes como uma comunicação entre culturas e único meio de aceder ao que foi enunciado em outras línguas faz com que a tradução se reduza a um simples meio de comunicação, de informação. E toda a literatura acaba se reduzindo a transmissão de dados, a informação sobre o conteúdo dos livros. Não se percebe que se retira assim toda a especificidade da coisa literária. O tradutor é frequentemente representado como um barqueiro: uma bela metáfora!; contudo, o que importa não é fazer passar de um lado ao outro, mas em que estado chega aquilo que foi transportado ao outro lado, à outra língua. Caronte também é um barqueiro. Mas ele transporta mortos, os que perderam a memória. E isso acontece com muitos tradutores e traduções (Meschonnic 1999:17). Uma boa tradução não deve ser pensada como uma interpretação, porque a interpretação é da ordem do sentido, do signo. E isso é radicalmente diferente do texto, que faz o que diz - o sentido está no seu modo de significar! -, que é transportador e é transportado. A interpretação (o sentido) é unicamente transportada. A boa tradução deve fazer e não somente dizer. Como texto, ela deve ser transportadora e transportada.

Meschonnic propõe uma poética do traduzir, na qual concebe a tradução de um texto como escritura de um texto, ou seja, como uma atividade translinguística que se relaciona com uma língua, com um inconsciente e com uma ideologia como sistemas, e que trabalha nos planos rítmicos, prosódicos e semânticos indissociavelmente, ou seja, como discurso. O discurso não pode ser pensado apenas com os conceitos da língua. Há comumente na concepção de tradução uma confusão entre o que seja da ordem da língua e o que seja da ordem do discurso. Traduzir não é passar o que é dito numa língua a outra, mas é produzir um discurso. Passar de uma língua a outra é cuidar apenas do sentido, da mensagem. O discurso é a atividade de um sujeito falante, é uma escritura, ou seja, a subjetivação que transforma a língua em texto. Não se traduz da língua. É o discurso e a escritura que é preciso traduzir. A tradução literária é um discurso que envolve rítmica, prosódia, polissemia; que integra sua situação, seu referente, e sobretudo o sujeito do discurso: ela faz da linguagem um significante generalizado: Ultrapassa-se o signo. Reduzir o discurso à língua é tornar a tradução mais linguística do que literária, é produzir uma tradução-língua, não uma tradução-texto. A tradução-texto é a tradução da enunciação, não do enunciado (1999:144). 
Há, além do sentido das palavras, um sentido menos aparente, e que sozinho cria em nós a impressão estética querida pelo poeta. É esse sentido que se trata de traduzir, é sobretudo nisso que consiste a tarefa do tradutor: Traduzir o que as palavras não dizem, mas o que elas fazem $^{10}$ (1999:55).

Um pensamento faz alguma coisa na linguagem, e é isso que ele faz que é preciso traduzir ${ }^{11}$ (Meschonnic 1999:23). Mas isso não se realizaria pelo apagamento do tradutor na tradução, porque o sentido literário precisa ser primeiramente apreendido; e não basta apreendê-lo, é preciso recriá-lo. "Isso exige o engajamento máximo de um sujeito específico, para que o sujeito do traduzir seja o sujeito do poema, para que haja invenção recíproca de um texto e do tradutor como sujeito desta atividade"12 (Meschonnic 1999:56). Que se possa falar do Poe de Baudelaire e daquele de Mallarmé, da Vulgata de Jerônimo, da Bíblia de Lutero, do Milton de Chateaubriand, da Eneida de Klossowsky e de Odorico Mendes, da Antígona de Hölderlin, e outros, isso mostra que a tradução exitosa é uma escritura, não uma transparência anônima, apagamento e modéstia do tradutor. O tradutor deve tornar-se um autor para que a tradução seja uma obra. Quanto mais o tradutor se inscreve como sujeito na tradução, mais, paradoxalmente, traduzir pode significar continuar o texto, num outro tempo, numa outra língua, fazendo um texto. Poética por poética.

Para subsistir ao lado do original, para atingir sua imortalidade, uma tradução precisa ser produzida a partir da significância e, em sendo histórica, atingir valores supra-históricos, supra-ideológicos, como o fez o original, tornarse texto. "A tradução não-texto envelhece: sendo passivamente a produção de uma ideologia, ela passa com esta ideologia”"13 (Meschonnic 1973:321). Um texto não cessa de se fazer, seu conhecimento é inesgotável, ele produz uma repetição indefinida de leitura; ele é um lugar de interações; é feito de conflitos, de contradições que não podem se resolver. Se elas se resolvem não há texto, há uma escritura variavelmente ideológica, exploradora mas não transformadora. "As contradições do texto são: da lógica do significante com a lógica do significado, do sujeito com o objeto, do dizer com o viver, do indivíduo com o social, da escritura com a ideologia. Onde não existem estas contradições funcionam as escrituras ideológicas”14 (Meschonnic 1973:40-41), não a arte mas o artefato, a reprodução. Quanto mais polissêmica, quanto menos marcada ideologicamente uma obra, um texto, uma tradução, maior sua arte, maior sua gama de leituras, seja quando de seu surgimento, seja através dos tempos.

\footnotetext{
10 “C'est qu'il y a, en plus du sens des mots, un sens moins apparent, et qui seul crée en nous l'impression esthétique voulue par le poète. Eh, bien, c'et ce sens-là qu'il s'agit de rendre, et c'est en cela curtout que consiste la tâche du traducteur. Traduire ce que les mots ne disent pas, mais ce qu'ils font”.

11 “Une pensée fait quelque chose au langage, et c’est ce qu’elle fait qui est à traduire”.

12 “Ce qui demande l'engagement maximal d'un sujet spécifique, pour que le sujet du traduire soit sujet du poème, pour qu'il y ait l'invention réciproque d'un texte et du traducteur comme sujet par cette activité”.

13 "La traduction non-texte vieillit: étant passivement la production d’une idéologie, elle passe avec cette idéologie".

14 "Les contradictions du texte sont: celle de la logique du signifiant avec la logique du signifié, celle du sujet avec l'objet, celle du dire avec le vivre, celle de l'individu avec le social, celle de l'écriture avec l'idéologie. Là où il n’y a pas ces contradictions fonctionnent les écritures idéologiques”.
} 
Walter Benjamin, embora expresse uma concepção de tradução de língua a língua, revela uma experiência de tradução que ultrapassa a noção de tradução fiel do sentido e remete à produção de nova textualização, ou seja, de um modo de significar:

A fidelidade na tradução da palavra isolada quase nunca pode reproduzir o sentido completo que possui no original. Pois este não se esgota na sua significação poética para o original, no pensado, mas a produz precisamente mediante o como o pensado está ligado ao modo de significar na palavra dada. ${ }^{15}(1980: 17)$.

O pensador alemão concebe a tradução como repoetização [Umdichtung], e a traduzibilidade como sendo característica das grandes obras, porque quanto maior for sua poeticidade, maior será sua traduzibilidade. A essência não está no comunicável, mas no poético, naquilo que é intuído, reconhecido, mas incomunicável.

Para Benjamin, tradução literária não é transmissão de sentido, de mensagem, não é comunicação. O tradutor que desejasse comunicar ao público obras que sua ignorância da língua o impede de saborear, não faria uma tradução, mas uma introdução, como diria Meschonnic. Apenas a traduçãointrodução, a tradução-língua faz concessões ao público. O tradutor que traduz para o público pretere o original, preferindo seu público. Para Walter Benjamin, uma tradução não é feita para os leitores que não entendem o original. Não é essa a essência de uma tradução literária.

Na concepção de tradução que tem o texto como unidade de tradução, há uma passagem do primado da língua e do dualismo do signo para o primado do discurso e o monismo do ritmo no discurso. O ritmo aqui deve ser entendido não no sentido tradicional, não como uma alternância formal entre tempos fortes e fracos, mas como a "organização do movimento da palavra na escritura”, "unidade de equivalência numa poética da tradução”16 (Meschonnic 1999:56), como a própria operação do sentido no discurso, o modo de significar. O objetivo da tradução não é mais o sentido comunicante, mas bem mais, aquilo que o inclui: o modo de significar. É ele que produz o "sentido menos aparente". A tradução se transforma se o ritmo entra em seu programa, e não por isso ela se torna mais difícil. Na prática, o cuidado com o ritmo leva à tradução, desde a observância de uma simples pausa no processo de uma enunciação do original, a um corte exato de grupos rítmicos, à manutenção de efeitos poéticos, de modalidades discursivas, à tradução da letra.

Se existe alguma fidelidade, ela só pode ser à letra (Berman 2012:98). Mas letra entendida nesse sentido bermaniano, o que não significa fidelidade à palavra. A letra está para a forma, para a materialidade, a corporalidade do texto, o ritmo do discurso, as cadeias do significante. A tradução da letra é uma tradução ética e poética, que se faz pela aceitação do Estrangeiro e seu modo de sig-

\footnotetext{
15 “Treue in der Übersetzung des einzelnen Wortes kann fast nie den Sinn voll wiedergeben, den es im Original hat. Denn dieser erschöpft sich nach seiner dichterischen Bedeutung fürs Original nicht in dem Gemeinten, sondern gewinnt diese gerade dadurch, wie das Gemeinte an die Art des Meinens in dem bestimmten Worte gebunden ist”.

16 "Le rythme, organisation du mouvement de la parole dans l'écriture, est alors l'unité d’équivalence dans une poétique de la traduction”.
} 
nificar. Por vezes, a tradução do Estrangeiro pode causar estranhamento, mas não é o simples produzir estranhamento que significa traduzir a letra, ou que esta consista unicamente disso. Traduzir o Estrangeiro não é de modo algum criar estereótipos, exotizar o estrangeiro. Isso seria permanecer na tradução da interpretação, na tradução do sentido. O estranhamento pode, porém, advir do fato de que a tradução da letra, ou tradução literal, no sentido bermaniano, consiste em, se necessário, violar a sintaxe da língua de chegada, em neologizá-la "Que [isso] ainda surpreenda, eis o que é surpreendente.” (2012:143) -, em manter no texto da tradução a obscuridade inerente ao original (2012:144), em ater-se à textura do original, em sugerir os jogos de palavras, em preservar os sistematismos da obra (tipo de frases, construções utilizadas, emprego de tempos, etc.), em buscar-e-encontrar o não-normatizado da língua de chegada para introduzir aí a língua estrangeira e seu dizer. Paradoxalmente, o nãonormatizado da língua de chegada é o lugar que ela tem de mais 'acolhedor', é o que indica o ser materno da língua materna (2012:175), é onde ela aceita o Outro (2012:95), porque, na sua maternalidade, é sempre um albergue para o estrangeiro.

A noção bermaniana de tradução da letra também pode ser percebida no pensamento do escritor e filósofo alemão Rudolf Pannwitz (1980:20):

Nossas traduções, também as melhores, partem de um axioma falso: elas querem germanizar o hindu, o grego, o inglês em vez de hinduizar, helenizar, anglecizar o alemão. Elas têm um respeito mais significativo diante dos próprios usos lingüísticos do que diante do espírito da obra estrangeira. O erro axiomático do tradutor é que ele aprisiona o estado casual da própria língua em vez de deixá-la se movimentar poderosamente pela língua estrangeira. Ele deveria, sobretudo se traduz de uma língua muito distante, observar cuidadosamente os elementos últimos da língua mesma, onde palavra, imagem, som pertencem a um só conjunto. Ele deveria expandir e aprofundar sua língua através da estrangeira. ${ }^{17}$

Seguindo a reflexão de Berman, podemos ainda nos perguntar: Mas por que retraduzir os clássicos hoje por um modo diferente daquele da tradição ocidental da tradução? Por que submeter nossas línguas a uma relação tão íntima e transformadora com línguas estrangeiras? Simplesmente porque chegamos a um momento de outra maturidade linguística e histórica, e queremos reabrir o acesso às obras que constituem nosso solo religioso, filosófico, literário e poético; às obras que modelaram decisivamente nosso modo de sentir e existir - Homero, Platão, a poesia latina, etc. - mas que ao mesmo tempo se esgotaram ao longo dos séculos. "A retradução moderna é uma memória repatriante, pois estas obras dominaram imperiosamente durante muito tempo nossa criação literária”

\footnotetext{
17 "Unsere übertragungen, auch die besten, gehn von einem falschen grundsatz aus, sie wollen das indische, griechische, englische verdeutschen, anstatt das deutsche zu verindischen, vergriechischen, verenglischen. Sie haben eine viel bedeutendere ehrfurcht vor den eigenen sprachgebräuchen als vor dem geiste des fremden werks... der grundsätzliche irrtum des übertragenden ist, dass er den zufälligen stand der eignen Sprache festhält, anstatt sie durch die fremde Sprache gewaltig bewegen zu lassen. Er muss, zumal wenn er aus einer sehr fernen sprache überträgt, auf die letzten elemente der sprache selbst, wo wort, bild, ton in eines geht, zurückdringen; er muss seine sprache durch die fremde erweitern und vertiefen”.
} 
(2012:159). E da reinstituição de uma relação com nossa origem cultural e literária depende, em parte, a instituição de uma relação não-etnocêntrica com as demais literaturas. A retradução dos clássicos, ademais de reabrir o acesso ao texto antigo - como já fizeram por primeira vez no Renascimento do século XVI - , é ainda a possibilidade de abertura e rejuvenescimento de nossa própria língua. E ainda, retraduzimos porque queremos ler traduções como obras, como clássicos.

Berman observa que há uma distinção importante entre dois espaços e dois tempos de tradução: o das primeiras traduções e o das retraduções (2012: 137). Aquele que retraduz depara-se com pelo menos dois textos: o original e uma tradução. Geralmente, é nesse espaço que a tradução produz suas obrasprimas, é nesse espaço que acontece a possibilidade da tradução da letra. Esse literalismo não é o modo fácil e primeiro, mas o modo último. A tradução literal é a expressão de uma intensa relação com a língua materna: a literalidade e a retradução são sinais de uma relação amadurecida com a língua materna, em que essa é capaz de aceitar a língua estrangeira (2012:138). E quanto maior o domínio que o tradutor possua da sua própria língua literária, unido a uma intuição da linguagem como um contínuo de ritmo, de prosódia, de semântica, maior lhe será a possibilidade de abrir-se para tal relação. O que se espera de nós é um pouco mais de ousadia.

Mauri Furlan

maurizius@gmail.com

Prof. Dr., Universidade Federal de Santa Catarina 


\section{Referências bibliográficas}

BAYET, Jean. Literatura latina. Trad. de José-Ignacio Ciruelo. Barcelona: Ariel, 1996.

Benjamin, Walter. “Die Aufgabe des Übersetzers” [1923], in Gesammelte Schriften. Band IV-1. Frankfurt am Main: Suhrkamp Verlag, 1980.

BERMAN, Antoine. La traduction et la lettre ou l'auberge du lointain [1985] / A tradução e a letra ou o albergue do longínquo. Trad. de Marie-Hélène Catherine Torres, Mauri Furlan, Andréia Guerini. $2^{\mathrm{a}}$ ed. Tubarão: Copiart, 2012.

Furlan, Mauri. La Retórica de la Traducción en el Renacimiento. Elementos para la constitución de una teoría de la traducción renacentista. Tese de doutorado. Barcelona: Universidad de Barcelona, 2002.

Meschonnic, Henri. Pour la Poétique II. Épistémologie de l'Écriture - Poétique de la Traduction. Paris: Gallimard, 1973. Poétique du Traduire. Paris: Verdier, 1999.

Mounin, Georges. Teoria e storia della traduzione. Turin: Einaudi, 1965.

PanNwitz, Rudolf. Apud Benjamin, Walter. "Die Aufgabe des Übersetzers" [1923], in Gesammelte Schriften. Band IV-1. Frankfurt am Main: Suhrkamp Verlag, 1980.

SCHLEIERMACHER, Friedrich. "Über die verschiedenen Methoden des Übersetzens [1813] / Dos Diferentes Métodos de Traduzir”, in Scientia Traductionis, n.09, 2011. 